\title{
REALISASI PENGENDALI INTENSITAS CAHAYA LAMPU DENGAN KONTROL SUARA DAN GOOGLE ANDROID SPEECH RECOGNITION API
}

\section{REALITATION OF LIGHT INTENSITY CONTROL WITH VOICE COMMAND AND GOOGLE ANDROID SPEECH RECOGNITION API}

\author{
Yuli Sun Hariyani, ST., MT. ${ }^{1}$, Cucu Fitri ${ }^{2}$, Sugondo Hadiyoso, ST., MT. ${ }^{3}$ \\ ${ }^{1,2,3}$ Prodi D3 Teknik Telekomunikasi, Fakultas Ilmu Terapan, Universitas Telkom \\ 1yulisun@telkomuniveristy.ac.id ${ }^{2}$ cucuy.fitri@gmail.com \\ ${ }^{3}$ sugondo@telkomuniversity.ac.id
}

\begin{abstract}
Abstrak
Dalam kehidupan sehari-hari setiap orang tidak dapat lepas dari cahaya untuk melakukan berbagai aktivitas di ruangan. Namun cahaya di ruangan harus disesuaikan dengan kebutuhan aktivitas masing-masing untuk menghindari pemborosan energi listrik. Terkadang sebagian orang sering lupa dan malas untuk mematikan atau menyalakan lampu dalam keadaan tertentu karena saklar yang digunakan masih manual. Oleh karena itu dibutuhan saklar yang dapat dikendalikan dari jarak jauh. Penelitian ini merealisasikan sistem pengendali lampu jarak jauh berbasis suara yang didukung oleh google voice recognition engine dan menggunakan android , tidak hanya mematikan dan menghidupkan lampu, namun juga mengatur lampu dengan beberapa level intensitas cahaya. Arduino Uno R3 digunakan sebagai piranti pengendali dengan Bluetooth sebagai media komunikasi antara smartphone dan mikrokontroller. Berdasarkan pengujian sistem dan alat yang direalisasikan, untuk pengujian di dalam ruangan dengan penghalang, maksimal jangkauan control mencapai 10 meter dengan respon lampu rata-rata 1,426 detik.
\end{abstract}

Kata kunci : Google Android Speech Recognition, Bluetooh, Smart Home

\begin{abstract}
In the daily life of each person can not be separated from light to perform various activities in the room. But the light in the room should be customized to the needs of each activity to avoid wasting electricity. Sometimes some people often forget and lazy to turn off or turn on the lights in certain circumstances due to the manual switch used. Therefore any 'switch that can be controlled remotely. This study realize remote lighting control system based voice supported by google voice recognition engine and use android, do not just turn off and turn on the lights, but also set lights with some level of light intensity. Arduino Uno R3 is used as a control device with Bluetooth as a communication medium between the smartphone and the microcontroller. Based on testing systems and tools that were realized, for testing in the room with the barrier, the maximum range of control reaches 10 meters with an average light response 1.426 seconds.
\end{abstract}

Keyword : Google Android Speech Recognition, Bluetooh, Smart Home 


\section{PENDAHULUAN}

Penghematan energi merupakan hal yang sangat penting bagi kehidupan manusia saat ini. Salah satu penyebab adalah pemborosan penggunaan energi pada sistem penerangan. Sistem penerangan ruangan pada umumnya hanya menggunakan prinsip on/off, yaitu hanya menyalakan dan mematikan lampu. Sistem tersebut terkadang kurang efektif karena tanpa menghiraukan kontribusi pencahayaan dari luar seperti pencahayaan matahari. Oleh karena itu diperlukan pengaturan penerangan, baik untuk faktor kenyamanan maupun efesiensi pemakaian energi listrik. Dan terkadang setiap disibukkan dengan kegiatan rutinitas sehari-hari sehingga sebagian orang lupa untuk mematikan atau menyalakan lampu pada keadaan tertentu. Pada umumnya orang menggunakan perantara kabel untuk mengendalikan perangkat elektronik. Saat ini perkembangan teknologi di bidang eletronika sudah maju, seperti adanya perangkat wireless yang dapat menggantikan peranan kabel dalam menggendalikan perangkat elektronik. Perangkat wireless tersebut menggunakan teknologi Bluetooth, infra merah, radio frekuensi sampai dengan telepon genggam. Pada awalnya telepon genggam hanya digunakan untuk berbagai macam kebutuhan multimedia dan sosial. Telepon genggam sekarang memiliki berbagai macam sistem operasi. Salah satu sistem operasi telepon genggam adalah sistem operasi Android. Android merupakan suatu sistem operasi telepon genggam yang berbasis Linux dan merupakan perangkat lunak open source.

Pada sistem operasi Android terdapat aplikasi untuk melakukan input suara yaitu Google Android Speech Recognition. Aplikasi ini merupakan aplikasi bawaan dari sistem operasi Android yang bisa dimanfaatkan untuk berbagai macam keperluan misalnya untuk mengetik SMS dan melakukan pencarian online hanya dengan inputan suara. Dari teknologi tersebut, dibuat sistem yang memungkinkan sebuah smartphone Android untuk dijadikan alat kendali intensitas cahaya lampu. Dengan adanya sistem ini maka kegiatan rutinitas sehari-hari dapat dilakukan dengan lebih nyaman dan sistem ini juga bermanfaat bagi semua orang untuk mencoba teknologi terbaru dan tentunya mempermudah dalam mengendalikan cahaya lampu dengan cukup memegang smartphone Android dan menginputkan suara tanpa harus menuju tempat pengendalian perangkat seperti saklar lampu yang masih manual.

\section{DASAR TEORI /MATERIAL DAN METODOLOGI/PERANCANGAN}

\subsection{Pulse Width Modulation (PWM)}

Merupakan suatu metode yang digunakan untuk mengontrol daya yang berkaitan dengan power supply, contohnya pada power supply PC. Selain fungsi PWM yang digunakan untuk mengontrol daya power supply, PWM juga dapat difungsikan sebagai penggerak perangkat elektronika, misalnya pada motor DC, mengatur gelap-terang nyala LED, pembangkit sinyal sinusoidal. Konsep kerja dari PWM adalah mengatur kecepatan, intensitas cahaya, membuat sinyal analog menggunakan 1 bit sinyal digital, ditunjukkan pada gambar dibawah ini:

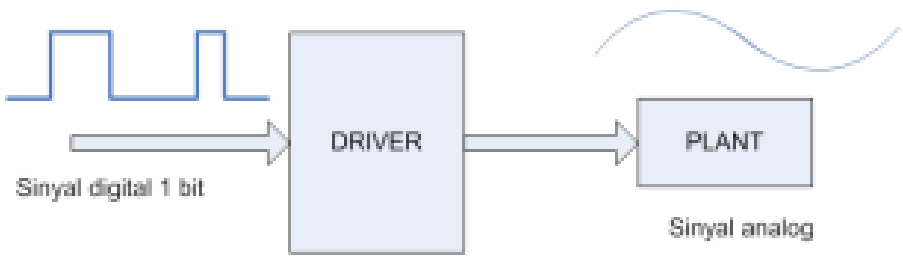

Gambar 1. Diagram Pengaturan dengan PWM

Sinyal dari PWM berupa gelombang kotak. Besar sinyal analog atau aksi pengaturan yang dihasilkan ditentukan oleh duty cycle sinyal PWM. Sinyal PWM pada umumnya memiliki 
amplitude dan frekuensi dasar tetap, namun memiliki lebar pulsa yang bervariasi, lebar pulsa PWM berbanding lurus dengan amplitodu sinyal asli yang belum termodulasi. Artinya sinyal PWM mempunyai frekuensi gelombang yang tetap namun duty cycle bervariasi (antara $0 \%$ hingga 100\%). Pada mikrokontroler ATMEGA328 pengaturan PWM dilakukan dengan mengatur nilai OCR pada timer yang digunakan[1]

\subsection{Google Android Speech Recognition}

Speech recognition atau pengenalan sinyal wicara menggunakan google voice dilakukan pada google server menggunakan algoritma HMM. Proses dimulai dari mengubah suara akustik menjadi kesatuan kata yang dilakukan oleh software. Akurasi pengenalan sinyal wicara bergantung pada jumlah kosa kata dan kemiripan dengan kata lain, speaker dependence vs. independence.[2] Yaitu sistem yang tidak menggunakan pelatihan yang disebut sistem "Speaker Independent" dan sistem yang menggunakan pelatihan yang disebut sistem "Speaker Dependent".

Pengenalan sinyal wicara dapat dibagi menjadi beberapa blok: ekstraksi ciri, pemodelan basis data akustik yang dibangun berdasarkan data pelatihan, dictionary, pemodelan bahasa dan algoritma speech recognition[3]. Sinyal suara analog sebelumnya harus di cuplik atau di-sampling dengan jarak waktu tertentu, di kuantisasi dan di kodekan menjadi sinyal digital. Ekstraksi ciri sinyal wicara dari database pelatihan akan digunakan untuk mengestimasi parameter dari model akustik. Model akustik mendefinisikan parameter dari elemen dasar yang dapat dikenali. Elemen dasar dapat berupa fonem atau kata.

Dictionary digunakan untuk menghubungkan model akustik dengan kosa kata. Model bahasa berfungsi mengurangi jumlah kombinasi kata berdasarkan aturan atau pola bahasa yang digunakan dan informasi statistic dari teks yang berbeda. Algoritma pengenalan sinyal wicara yang menggunakan HMM (Hidden Markov Model) menggunakan fonem sebagai unit pemodelan. Outpit dari algoritma ini adalah state fungsi probabilistic tersembunyi dan tidak bisa di gambarkan secara spesifik. Sistem pengenalan sinyal wicara mengasumsikan bahwa sinyal wicara adalah realisasi pesan yang disusun dari satu atau lebih simbol[4].

\section{PERANCANGAN SISTEM}

Sistem yang dirancang terdiri 3 bagian utama yaitu 1. software aplikasi sebagai antarmuka pengendali, 2. sistem Bluetooth sebagai transmisi antara android dan alat serta 3. Rangkaian pengendali intensitas lampu sebagaimana yang ditunjukkan pada gambar 1.
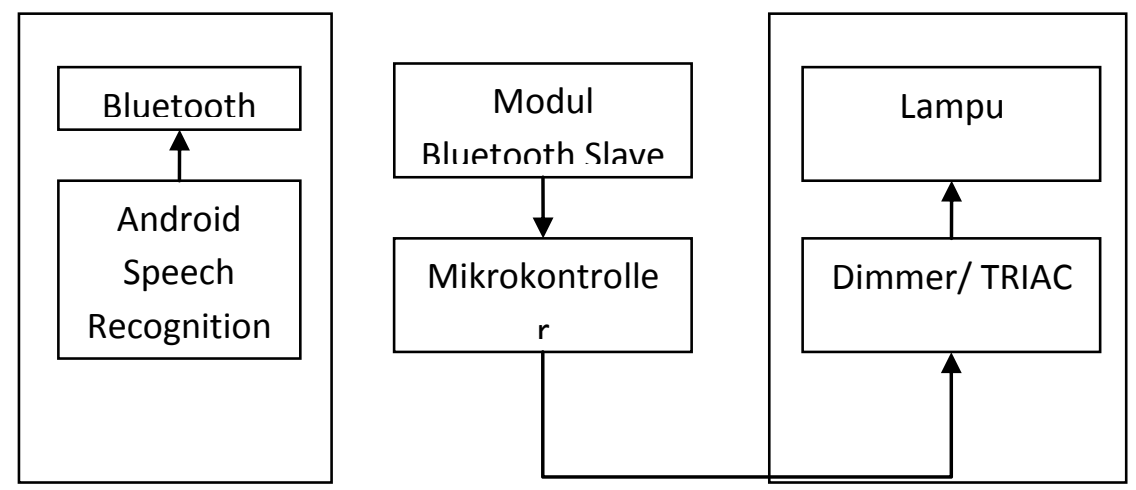

Gambar 1. Blok Diagram Umum 


\subsection{Perancangan Software}

Pada perancangan aplikasi android, terdapat beberapa perangkat lunak pendukung untuk membuat sebuah aplikasi android, yaitu :

- Java Development Kit (JDK)

- Android Software Development Kit (Android SDK)

- Ecipse Juno

- Android Development Tools (ADT 10.0.1)

Perancangan aplikasi dapat dilihat pada sequence diagram pada gambar 2, sedangkan beberapa perintah yang diinputkan untuk mengontrol intensitas lampu dapat dilihat pada tabel 1

Tabel 1. Perintah suara yang digunakan

\begin{tabular}{|c|c|}
\hline $\begin{array}{c}\text { Perintah Suara } \\
\text { Satu (1) }\end{array}$ & $\begin{array}{c}\text { Kondisi Lampu } \\
\text { 0\% }=\text { mati }\end{array}$ \\
\hline Dua (2) & $25 \%$ redup \\
\hline Tiga (3) & $50 \%$ redup \\
\hline Empat (4) & $75 \%$ terang \\
\hline Lima (5) & $100 \%$ terang sekali \\
\hline
\end{tabular}

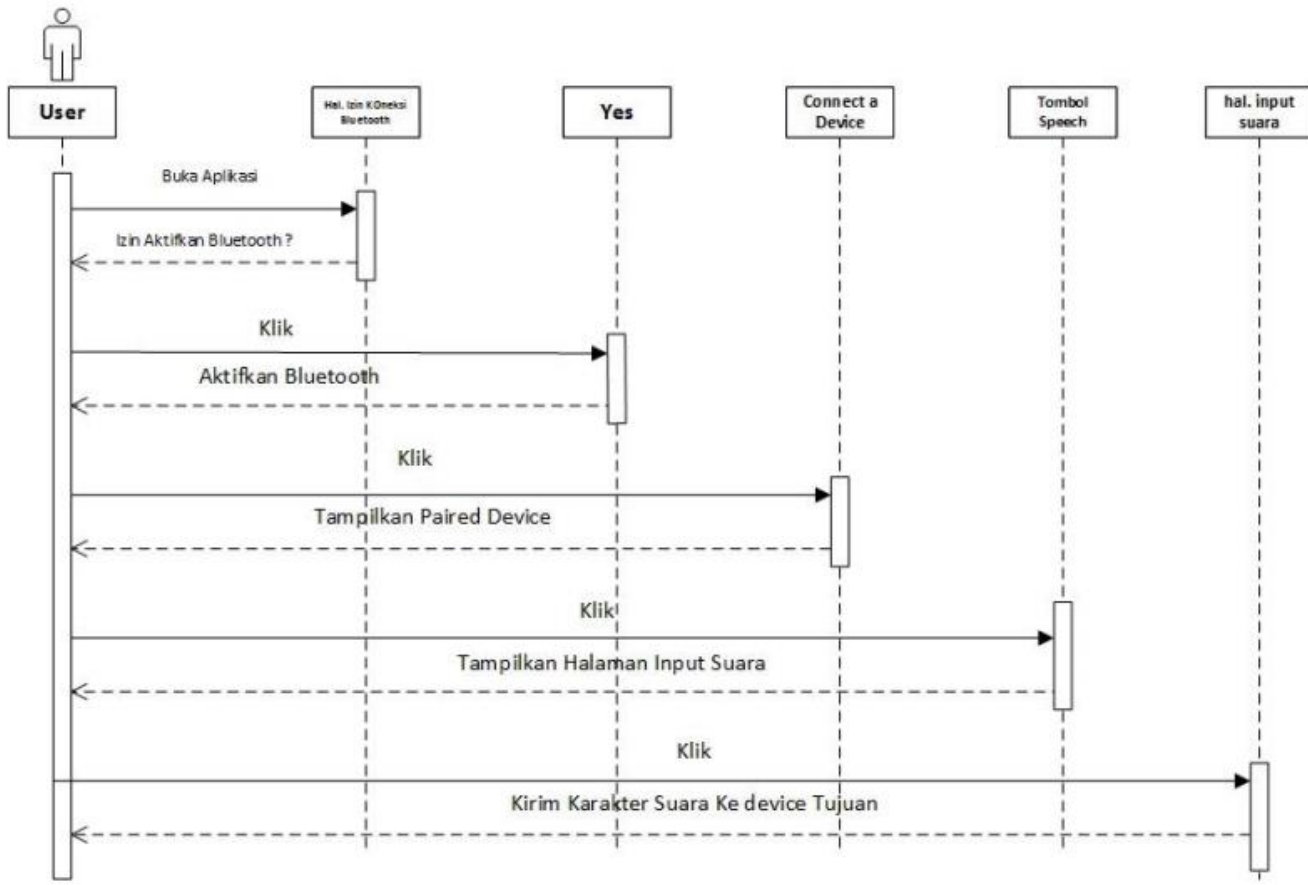

Gambar 2. Sequence Diagram

\subsection{Perancangan Hardware}

Pada perancangan rangkaian pengendali intensitas lampu, spesifikasi yang digunakan antara lain : 
a. Catu daya AC 220 V yang berasal dari PLN.

b. Adaptor 5-9 volt untuk mensuplai tegangan mikrokontroller

c. Arduino UNO ATmega328, sebagai pengolah data yang diterima dari modul Bluetooth kemudian mengolahnya menjadi intruksi. Dalam sistem ini menggunakan pin PWM, pin 5 volt, ground dan pin 2 sebagai zero crossing detector.

d. Modul Bluetooth Slave, berfungsi sebagai penerima data dari smartphone android yang akan diteruskan ke mikrokontroller

e. Rangkaian Dimmer / TRIAC

f. Lampu pijar

Sistem yang dirancang lebih jelasnya dapat dilihat pada gambar 3

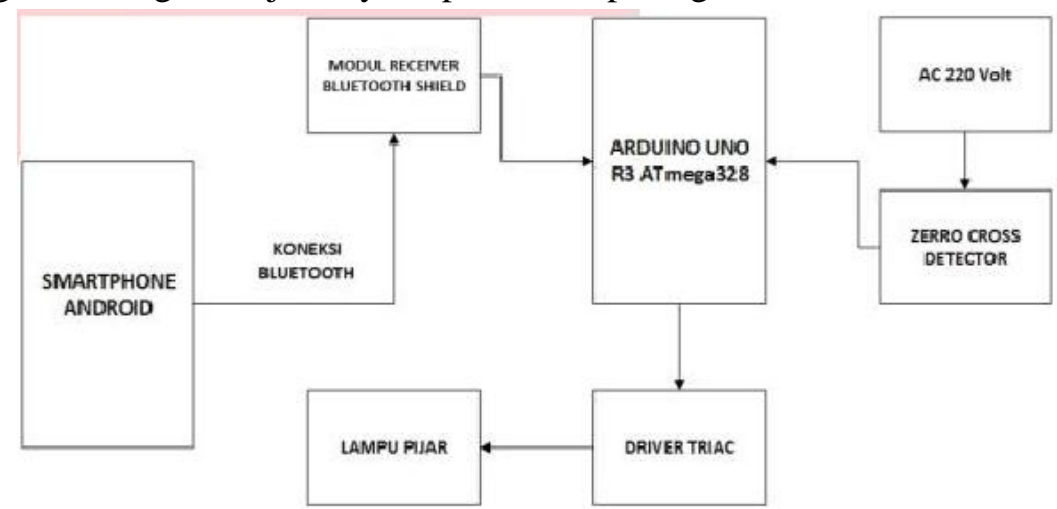

Gambar 3. Blok Diagram Sistem Pengendali Intensitas Lampu

- Rangkaian Dimmer

Pada rangkaian dimmer yang dirancang terdapat rangkaian Zero Crossing Detector yang berfungsi mendeteksi zero point sekaligus mengubah suatu sinyal sinusoidal menjadi sinyal kotak. Sinyal keluaran rangkaian Zero cross detector ini akan menjadi masukan mikrokontroler, oleh karena itu dibutuhkan juga komponen optocoupler 4N35 yang mampu memisahkan tegangan $5 \mathrm{~V}$ dan $220 \mathrm{~V}$. Keluaran Sinyal pulsa dari PWM akan menjadi input komponen TRIAC yang berfungsi sebagai switching regulator AC, sehingga tegangan yang masuk pada lampu bervariasi sesuai dengan pulsa keluaran PWM.

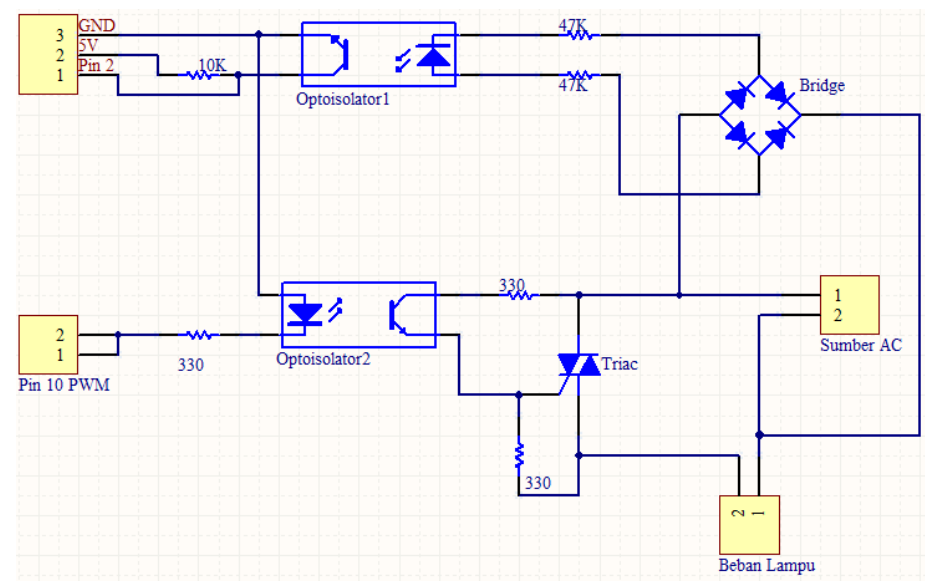

Gambar 4. Rangkaian TRIAC dan Zero Crossing Detector 


\section{HASIL DAN PEMBAHASAN}

Pengujian pertama dilakukan untuk melihat kemampuan aplikasi dalam mendeteksi perintah suara. Dari hasil pengujian menunjukkan bahwa pada jarak 5-15 cm untuk kondisi tenang/ tanpa noise tingkat keberhasilan akurasi suara 100\%, menunjukkan proses speech recognition pada perintah suara berhasil dengan baik. Pada jarak $40 \mathrm{~cm}$ tingkat keberhasilan hanya $10 \%$, dipengaruhi sensitivitas mikrofon pada smartphone. Sedangkan untuk kondisi dengan noise didapatkan tingkat keberhasilan maksimal $70 \%$ pada jarak $5 \mathrm{~cm}$.

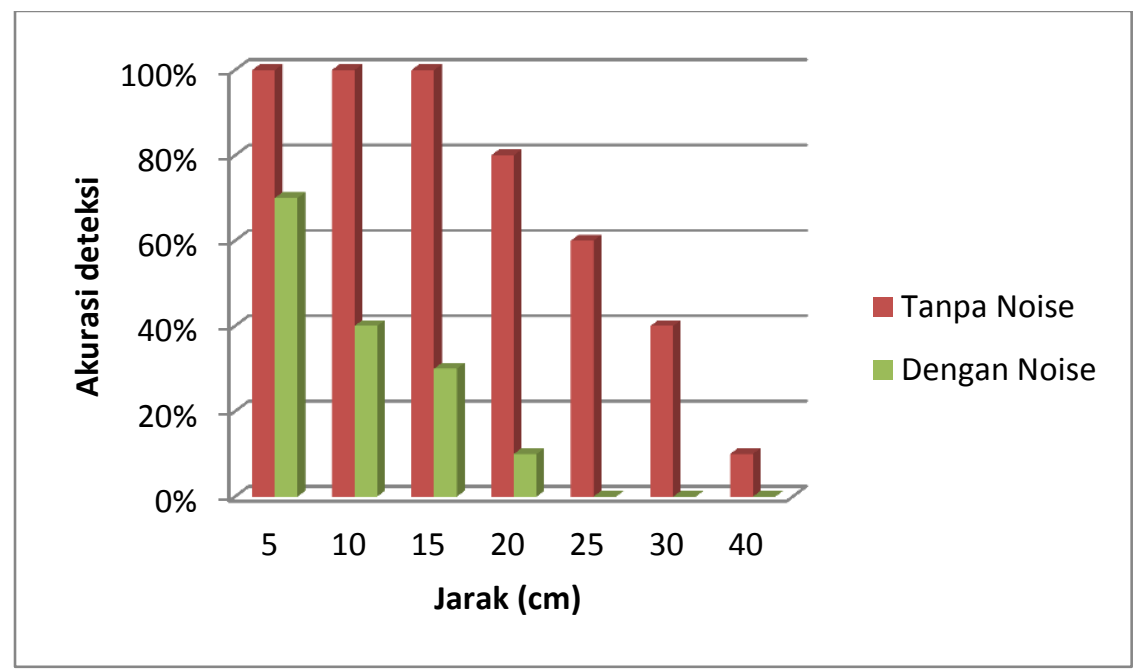

Gambar 5. Hasil Pengujian jarak pada speech processing

Pengujian berikutnya merupakan pengujian intensitas lampu melalui kontrol PWM. Darii pengujian terlihat lebar pulsa melebar dan menyempit mengikuti perintah kontrol intensitas lampu.

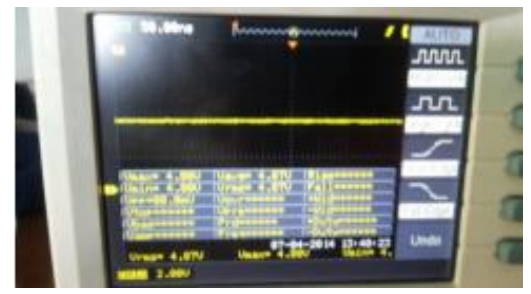

a. duty cycle $100 \%, \mathrm{~T}=10 \mathrm{~ms}$

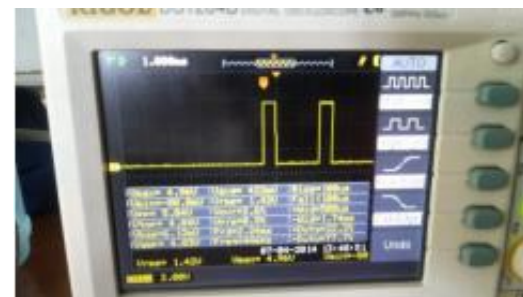

d. duty cycle $25 \%, \mathrm{~T}=2.24 \mathrm{~ms}$

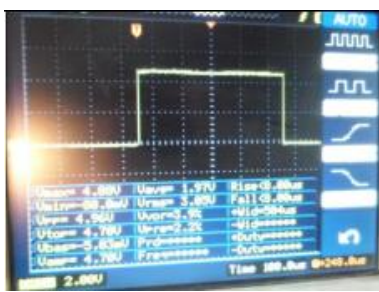

b. duty cycle $75 \%$, $\mathrm{T}=7.7 \mathrm{~ms}$

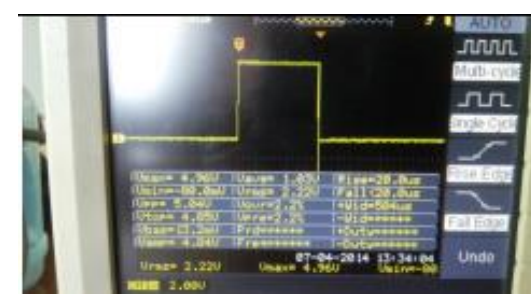

c. duty cycle $50 \%, \mathrm{~T}=4.8 \mathrm{~ms}$

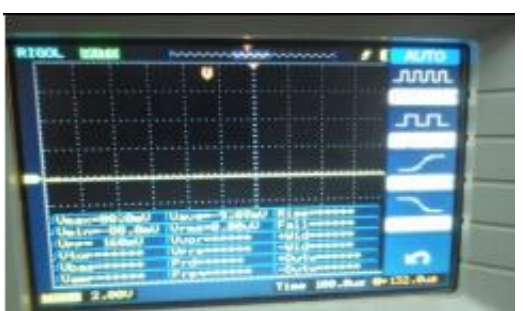

e. duty cycle $0 \%, \mathrm{~T}=0 \mathrm{~ms}$

Gambar 6. Hasil pengujian sinyal keluaran PWM

Untuk pengujian secara keseluruhan dilakukan pada kondisi di dalam ruangan dengan kondisi NLOS seperti ditunjukkan pada gambar 7. Hasil pengujian terlihat pada tabel 2. Koneksi 
Bluetooth dapat menjangkau hingga jarak 10 meter dengan kondisi terdapat halangan dinding/ tembok. Semakin jauh jarak perintah maka waktu yang diperlukan hingga lampu merespon perintah juga semakin lama dengan rentang waktu respon 1-5 detik.

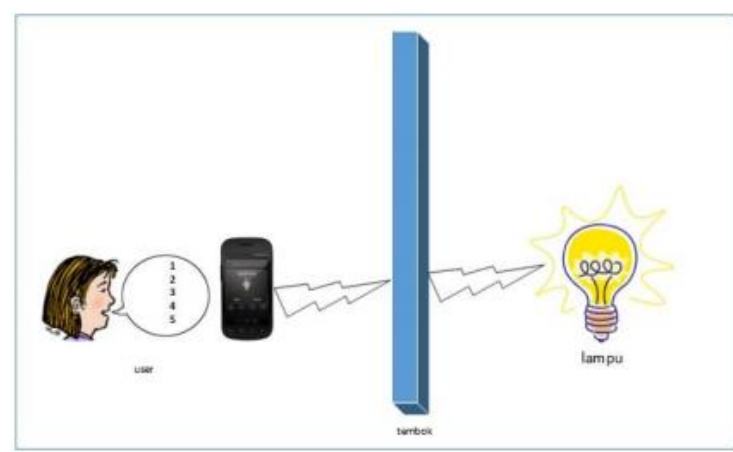

a. scenario pengujian

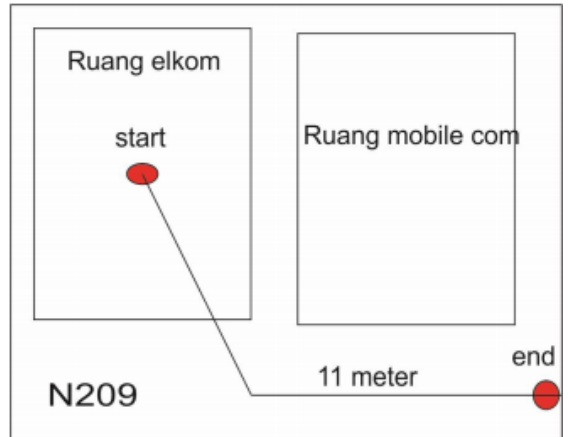

b. denah ruang pengujian

Gambar 7. Pengujian Sistem Keseluruhan

Tabel 2. Hasil Pengujian Sistem Keseluruhan

\begin{tabular}{|c|c|c|c|c|c|c|c|}
\hline \multirow{2}{*}{$\begin{array}{c}\text { JARAK } \\
\text { (meter) }\end{array}$} & \multirow{2}{*}{ Percobaan } & \multicolumn{5}{|c|}{ PERINTAH SUARA / Respon lampu (detik) } & \multirow{2}{*}{ STATUS } \\
\hline & & "1" & "2" & "3" & "4" & "5" & \\
\hline \multirow{5}{*}{2} & 1 & 1,000 & 1,008 & 1,000 & 1,000 & 1,100 & Terkoneksi \\
\hline & 2 & 1,005 & 1,000 & 1,180 & 1,100 & 1,090 & Terkoneksi \\
\hline & 3 & 1,090 & 1,100 & 1,009 & 1,300 & 1,098 & Terkoneksi \\
\hline & 4 & 1,000 & 1,000 & 1,000 & 1,010 & 1,007 & Terkoneksi \\
\hline & 5 & 1,200 & 1,100 & 1,200 & 1,070 & 1,000 & Terkoneksi \\
\hline \multirow{5}{*}{4} & 1 & 1,023 & 1,098 & 1,053 & 1,700 & 1,900 & Terkoneksi \\
\hline & 2 & 1,050 & 1,067 & 1,102 & 1,200 & 1,800 & Terkoneksi \\
\hline & 3 & 1,067 & 1,000 & 1,045 & 1,005 & 1,200 & Terkoneksi \\
\hline & 4 & 1,000 & 1,070 & 1,120 & 1,006 & 1,400 & Terkoneksi \\
\hline & 5 & 1,098 & 1,089 & 1,202 & 1,001 & 1,000 & Terkoneksi \\
\hline \multirow{5}{*}{6} & 1 & 1,060 & 1,080 & 1,300 & 1,037 & 1,089 & Terkoneksi \\
\hline & 2 & 1,094 & 1,056 & 1,050 & 1,079 & 1,023 & Terkoneksi \\
\hline & 3 & 1,005 & 1,078 & 2,009 & 1,056 & 1,004 & Terkoneksi \\
\hline & 4 & 1,044 & 1,099 & 1,056 & 1,045 & 1,056 & Terkoneksi \\
\hline & 5 & 1,907 & 1,234 & 1,049 & 1,256 & 1,971 & Terkoneksi \\
\hline \multirow{5}{*}{8} & 1 & 1,900 & 1,900 & 1,645 & 2,000 & 5,005 & Terkoneksi \\
\hline & 2 & 1,086 & 1,307 & 1,976 & 1,904 & 1,006 & Terkoneksi \\
\hline & 3 & 1,605 & 1,085 & 1,049 & 2,001 & 1,090 & Terkoneksi \\
\hline & 4 & 1,086 & 1,060 & 1,045 & 1,020 & 4,000 & Terkoneksi \\
\hline & 5 & 1,901 & 1,080 & 1,027 & 1,960 & 1,098 & Terkoneksi \\
\hline \multirow{5}{*}{10} & 1 & 1,789 & 1,900 & 1,336 & 2,073 & 2,909 & Terkoneksi \\
\hline & 2 & 1,754 & 1,956 & 1,850 & 2,149 & 2,014 & Terkoneksi \\
\hline & 3 & 1,892 & 2,100 & 3,000 & 1,354 & 2,304 & Terkoneksi \\
\hline & 4 & 1,999 & 1,698 & 1,956 & 2,000 & 2,091 & Terkoneksi \\
\hline & 5 & 1,357 & 2,001 & 1,549 & 2,001 & 3,771 & Terkoneksi \\
\hline \multirow{5}{*}{11} & 1 & & & & & & Tidak Terkoneksi \\
\hline & 2 & & & & & & Tidak Terkoneksi \\
\hline & 3 & & & & & & Tidak Terkoneksi \\
\hline & 4 & & & & & & Tidak Terkoneksi \\
\hline & 5 & & & & & & Tidak Terkoneksi \\
\hline
\end{tabular}




\section{KESIMPULAN}

Dari pengujian yang dilakukan, untuk kondisi di dalam ruangan dengan penghalang, jarak jangkau maksimal sistem pengendali intensitas cahaya lampu dengan kontrol suara melalui bluetooth adalah 10 meter, dengan respon waktu antara 1-5 detik. Untuk kondisi tanpa noise, perintah berhasil dikenali dengan akurasi $100 \%$ pada jarak maksimal $15 \mathrm{~cm}$, sedangkan untuk kondisi dengan noise, perintah berhasil dikenalli dengan akurasi 100\% hanya pada jarak $5 \mathrm{~cm}$.

\section{DAFTAR PUSTAKA}

[1] Heryanto, Ari dan Wisnu Adi, 2008. Pemrograman Bahasa C untuk Mikrokontroler ATMEGA 8535. Yogyakarta: Penerbit Andi

[2] J. Tebelskis, Speech Recognition using Neural Networks, Pittsburgh: School of Computer Science,Carnegie Mellon University, 1995.

[3] Abdul Kadir, 2012. Panduan Praktis Mempelajari Aplikasi Mikrokontroler dan Pemograman menggunakan Arduino. Bandung: Penerbit Andi

[4] Romy Budhi Widodo, 2009. Embedded System. Bandung: Penerbit Andi

[5] Nazruddin, 2012. Pemprograman Aplikasi Mobile Smartphone dan Tablet PC Berbasis Android. Bandung: Informatika

[6] Reddy, B. Raghavendhar, E. Mahender. Speech toText Conversion using Android Platform. International Journal of Engineering Research and Aplication. Vol.3, Issue 1. JanuaryFebruary 2013, pp.253-258.

[7] S. J. Young et al., "The HTK Book", Cambridge University Engineering Department, 2006. 